\title{
An Evaluation of Factors That Contributeto English Second Language Acquisition in the Upper Primary Phase of an Urban School in Namibia: A Case Study
}

\author{
Ms. Aletta Mweneni Hautemo \\ Lecturer \\ Education Department \\ University of Namibia \\ Windhoek \\ Mr. Lukas Homateni Julius \\ Lecturer \\ Language Centre \\ University of Namibia \\ Windhoek
}

\begin{abstract}
Majority of Namibian learners are not native speakers of English, that is, they barely speak English in their homes. Yet English is the medium of instruction in many Namibian schools. Many Namibian learners therefore face the double challenge of acquiring the English as the language of teaching and learning (Medium of Instruction) and at the same time developing the appropriate reading and writing proficiency needed to meet the requirements of the curriculum. This situation has created numerous teaching and learning problems which ultimately contribute to poor literacy levels among many Namibian learners. This paper focuses on language acquisition and literacy. It explores factors that contributes to effective English language acquisition as well as investigate and evaluate how the school context supports English language acquisition of the Upper Primary learners at an urban school in Namibia. Since the study targeted young learners, it has covered their reading skills, reading tools and resources such as the library and classroom which provides a rich learning environment. A qualitative interpretive approach was used to explore the factors that contribute to effective learners' English second language acquisition. The theoretical framework was informed by Krashen"s conception of acquisition (1981; 1982). Data collection methods consisted of questionnaires and interviews were used. The findings indicated that the provision of well-structured classroom activities containing comprehensible input structures a bit beyond the learners current level - and a low affective filter to allow them to acquire the second language easily. Moreover, errorbased activities help learners to test hypothesis, revise and modify them and in the process develop good language awareness skills that help them to acquire and learn the language consciously. This paper suggests that a good supporting environment for reading, which is scaffold by enough assistance by the teachers and peers helps learners develop good language acquisition and learning skills.
\end{abstract}

\section{Keywords: language acquisition, language learning, input hypothesis, comprehensible input, monitor hypothesis, reading}

\section{Subject classification: English Language Education}

\section{INTRODUCTION}

Language provides one of the most readily accessible windows into the nature of human mind. Children acquire a new language almost the sameway as they acquire their home language at school and in their surroundings. They learn by listening and observing, by imitating, by trying to communicate and getting feedback. Krashen (1981, 1982) describes this often unconscious kind of learning as acquisition. The grammars of both languages (home language and second language) contrast a lot. Where two languages differ we would expect errors and those errors in the second language are seen as the result of the first language' habits interfering with the acquisition of the habits of the second (Fries, 1972, cited in Hakuta and Cancino 1977).

Reading remains an integral tool in Second language acquisition as asserted by AlKialbi (2015, p. 14) that, "reading is an essential skill for English as a second (ESL)/foreign language (EFL) students; and for many, reading is the most important skill to master. In Africa, particularly in the indigenous Namibian communities, reading has never been utilised and considered in many home steads. As such, many children are introduced to reading at school where they acquire language with difficulties and much effort and instruction. Thus, reading becomes a complex activity for them which involves less background knowledge, bottom-up and top-down processing (source). AlKialbi maintains that with strengthen reading skills, ESL/EFL readers will make greater progress and attain greater development in all academic areas (p. 14).

\section{Purpose of the study}

The purpose of the study is to explore factors that contributes to English second language acquisition, as well asto investigate and evaluate how the school context supports language acquisition of the upper primary phase learners at an urban school in Namibia. To achieve this goal, this study was guided by the following research questions: 
a. What are the factors influence or motivate learners to learn English Second language?

b. What role do teachers as part of the school context play in the acquisition of English?

c. How does reading influences learners'English language learning?

\section{LITERATURE REVIEW}

Over the past years until the present, various language theorists and socio-linguists have contributed to and debated on the issue of language acquisition and learning. Some of those ideas are:

\section{i. Theoretical Perspectives on language acquisition}

When exploring the roles played by social activists in language acquisition and learning, we see no better place to begin than by exploring Vygotsky's work, for we believe he was the first among modern psychologists to talk about mechanisms through which the social culture and language become part of human nature, and hence of cognition. From social constructivists' point of view, it is asserted, individual cognition is largely influenced by cultural, social and linguistic contexts in which it occurs (Vygotsky, 1981). Vygotsky explained that language is not merely an expression of the knowledge the child has acquired, but it is a correspondence between thought and speech. This means that, to acquire second language, learners should have the ability to understand certain thought and be able to comprehend it. Even though most of Vygotsky's work on language is referred to as a view of child's cognitive development, we can still apply it to intermediate students' situation for as Vygotsky asserts "any analysis of the origin of uniquely human form of behaviour (should be based on the) unity of perception, speech, and action" (Vygotsky, 1978, p.26). This further means that for leaners to develop cognitively, language should be a crucial tool for determining how the child will learn to think because advance modes of thoughts are transmitted to the child by means of words (Murray, 1993). The role of scaffolding and the Zone of Proximal Development (Vygotsky, 1978) cannot be under emphasised in the role of language acquisition. Donato (1994) defined scaffolding as a "situation where a knowledgeable participant can create supportive conditions in which the novice can participate, and extend his or her current skills and knowledge to higher levels of competence" (p. 40), and Schumm (2006) construed scaffolding as "providing support for students in their language, and then gradually diminishing the support as students become more independent" (p530).. This is important in acquiring a new language and also in developing new learning skills such as reading. This is also essential in investigating the role or authenticity of the environment in learners' language acquisition and learning. The linguist Noam Chomsky as cited in Lightbown and Spada (1999) claims that children are biologically programmed for language and that language develops in the child just the same way that other biological function develop. The environment makes a basic contribution - in this case the availability of people who speak to the child, and then the child's biological endowment, will do the rest (p. 15). According to Chomsky as cited in Kavanaugh and Mattingly (1972), a child does not only need to speak the language to learn or know it, he also needs to be able to develop literacy skills. One of the crucial points in language acquisition according to Chomsky in is reading. He pointed out that reading is a secondary and rather special sort of activity that relies critically upon the reader's awareness of primary activities (speaking and listening). Whereas Vygotsky and Chomsky work emphasises language as a tool for child development; Krashen $(1981,1982)$, emphasises on second language acquisition and learning. He asserts that "acquisition requires meaningful interactions in the target language - natural communication - in which speakers are concerned; not with the form of their utterances but with the messages they are conveying and understanding". He further pointed out that, the best methods are therefore those that supply 'comprehensible input' in low anxiety situations, containing messages that students really want to hear. These methods do not force early production in the second language, but allow students to produce when they are 'ready', recognizing that improvement comes from supplying communicative and comprehensible input, and not from forcing and correcting production (Schultz, 2007).

\section{ii. The differences between language acquisition and language learning}

Krashen $(1981,1982)$ asserts that human beings have two different ways to develop competence in a language: language acquisition and language learning. Language acquisition is a subconscious process. People are not consciously aware of grammatical rules of the language, but rather develop a 'feel' for correctness. In a non-technical language, acquisition is 'picking up' a language. Language learning on the other hand refers to the 'conscious' knowledge of a second language, knowing the rules, being aware of them and being able to talk about them. Thus, language can be compared to learning about a language (Wilson, 2000). Competence in learning language is gained through 'Monitor' where language is modifies or corrected after a moment of production. Krashen's ideas were comprehended by Haynes (1998, 2005) who emphasised that in order to acquire language; the emphasis is on the text of the communication and not on the form. Language learning on the other hand is a result of direct instruction in the rules of language. Learners should have conscious knowledge of the new language and can talk about that knowledge.Therefore learners who have passed the lower primary (beginner) level and currently in their intermediate level, have already acquired Basic English skills, as such they are still experiencing the above mentioned language development stages. These learners are learning the language which they have not yet fully acquired consciously thorough day-to-day classroom teaching and subconsciously through their daily interaction with their peers and through reading and listening. This further means that, it is not enough to acquire the language, learners need to continuously learn about it and for them to learn, and they need motivational and affective filters from their teachers and the school community at large. According to Krashen's affective filter hypothesis ${ }^{1}$, acquisition is more important than learning. In order to acquire the language, two conditions are necessary. The first one is

\footnotetext{
${ }^{1}$ Affective filter hypothesis claims that learners with high motivation, self-confidence, a good self-image and a low level of anxiety are better equipped for success in second language acquisition. Low motivation, low self-esteem and debilitation anxiety can combine to raise affective filter and form a 'mental block' that prevents comprehensible input from being used for acquisition. (http://www.sk.com.br/sk-krash.html)
} 
comprehensible input containing $i+1$ - structures a bit beyond the acquirers current level - and secondly, a low or weak affective filter to allow the input 'in'. Krashen (1982) asserts that "acquisition requires meaningful interactions in the target language - natural communication - in which speakers are concerned; not with the form of their utterances but with the messages they are conveying and understanding". He further pointed out that, the best methods are therefore those that supply 'comprehensible input' in low anxiety situations, containing messages that students really want to hear. These methods do not force early production in the second language, but allow students to produce when they are 'ready', recognizing that improvement comes from supplying communicative and comprehensible input, and not from forcing and correcting production. (Schultz, 2007). Classroom teaching helps when it is provided with necessary comprehensible inputs in a low anxiety atmosphere to students who are not yet at the level of language competency. It should provide learners with communication tools that makes better use of the outside world and provide conscious learning. (Wilson, 2000). The teacher is the one who contextualise and modify the language to enable learners to negotiate input. This learning involve the Monitor hypothesis (Krashen, 1981) which crashes describes as a control system that can alster the output of the acquisition system according to learned rules, time and focus. This can help learners to ask for clarification and have control over where the interaction is going.

\section{iii. Factors involved in the Second Language Acquisition (SLA)}

Research has found various factors that influence language acquisition (Dornyei 1998, Williams \& Burden 1997, Peirce 1995). These include factors such as motivation, confidence, identity and aptitude. According to Krashen (1981), language acquisition is influences by attitudes and motivation while learning is influences by aptitudes and ability. Motivation can be intrinsically (motivation from within -learning the language for its beauty and for the joy of it) or extrinsically (motivation from outside - learning the language for the career) or integrative (learning the language of the community in order to be accepted) and instrumental (learning a language with a more utilitarian purpose such as achieving a higher social status). Clement, Dornyei \& Noels (1994), introduced a term 'linguistic self-confidence' that refers to the fact that people learn the language because they have experience success in it, their anxiety in it is low and they have positive contact with people who speak the language they are learning. Language plays an important part in constructing who we are in any of those roles (Rhodes University, 2010, p. 6). This creates our identities within that language and Pierce (1995) referred those roles as investments that help people to get along in the social contexts and they develop goodAptitudewhichinvolves the ability of learners to identify, memorise and understand the language syntactic and semantic structures.

\section{iv. Roles of reading as part of Second language acquisition}

As part of language learning, reading is one component that comprehends the language acquirers' knowledge. Cazden (1992, p.46) pointed out that, "reading is an interactive set of parallel process, attending simultaneously to different level of text structures; it is also a constructive process". Consequently, teachers must help children bring out in mind whatever knowledge they have that is relevant to the text at hand and try to find ways to help them acquire new knowledge and new vocabulary throughout their school career. According to Cunningham and Stanovich (2003), the difference between children with extensive vocabularies and those with limited vocabularies is the amount of prints they are exposed to. This then bring about the Matthew Principle ${ }^{2}$ in operation, whereby the more the children read, the wider their vocabularies become and the better they read. Furthermore, Cunningham and Stanovich, (1998) proposed what they call 'positive feedback loop', which is a reciprocal effect in which reading increase learners' ability to read. For vocabulary to occur children must be exposed to words that are relatively rare and it is prints that provides many such words and learning opportunity. As learners read a lot, their knowledge and understanding is enhanced and they will experience good and fulfilling results from reading. Home background plays a crucial role in reading development. Murray (2006) pointed out that"children who grow up in homes where there are plenty of books and whose parents read to them have an advantage; when they (parents) read to their children, they read like their teachers... therefore, they find it relatively easy to see themselves as readers and writers and this is referred to as "emergent literacy"' (p.6). This realisation was further supplemented by Cunningham and Stanovich (1998) who stated that, students who get off to a fast start in reading are more likely to read more over the years, and this very act of reading can help children compensate for modest levels of cognitive ability by building their vocabulary and general knowledge. Those who read a lot will enhance their verbal intelligence; as such reading will make them smarter (p.7).

\section{METHODOLOGY}

This qualitative case study consisted of a small sample of 7 teachers and 30 learners (14 Grade 5 and 16 Grade 6 ), whereby 18 were girls and 12 were boys, purposively selected based on their age (10 - 14-16), home language, and the community they originated from. The selected research site isa multi-cultural and multi-lingual school which consists of teachers and learners from various spheres of life, be it regional, national or international. Majority of the school members, about $80 \%$ of teachers and learners are native Oshiwambo speakers who rose from different Owambo tribes and share common language characteristics, through different Oshiwambo dialects, i.e. Oshikwanyama, Oshindonga (two main Oshiwambo dialects which are written and available in literature), Oshikwambi, Oshingandjera, Oshikwaluudhi, Oshimbadja and Oshikolonkadhi. The remaining $20 \%$ is of those cross-cultural learners from other regions, with a few from Caprivi, now known as Zambezi, and Kavango, three Portuguese learners and two Zimbabwean learners. Two of the teachers are Nigerian, of Hausa and Kanuri home languages, working as volunteers through the Nigerian embassy. Three data collection tools were used beginning with a focus group interview with learners to discuss about their involvement with the English language, language exposure at school, home and in the community. Although the teachers were busy and reluctant to attend an interview, we managed to conduct an interview with 7 (3 language teachers and 4 content

\footnotetext{
${ }^{2}$ Matthew Principle is based on the biblical phrase in that the rich get richer and the poor get poorer.
} 
subject teachers) teachers to discuss about their experience with English language use at home and in school and also to see how often they engaged learners in reading activities. Secondly,we decided to design a semi-structured questionnaire to get qualitative data from learners regarding their language exposure and experiences. A sample of 30questionnaires were handed to 30 selected learners based on their home languages, their English performances in the classroom.Lastly, we observed the language learning environment in the school, learners' interaction with their peers in and out of the classroom, how the language teachers involve learners in language negotiations and how they organise comprehensible input to facilitate learners' language learning. Observed comments were noted as field notes.

\section{FINDINGS}

Two primary premises behind this study were Second Language Acquisition (SLA)and the influence of reading on second language acquisition and learning.

\section{i. Motivation to learn English second language}

All 30 respondents indicated that they feel lucky to learn English because it is the official language and the medium of instruction and communication with teachers and their peers at school. The respondents feel that English motivate them to talk to foreign learners and visitors who come to their school or in their communities.

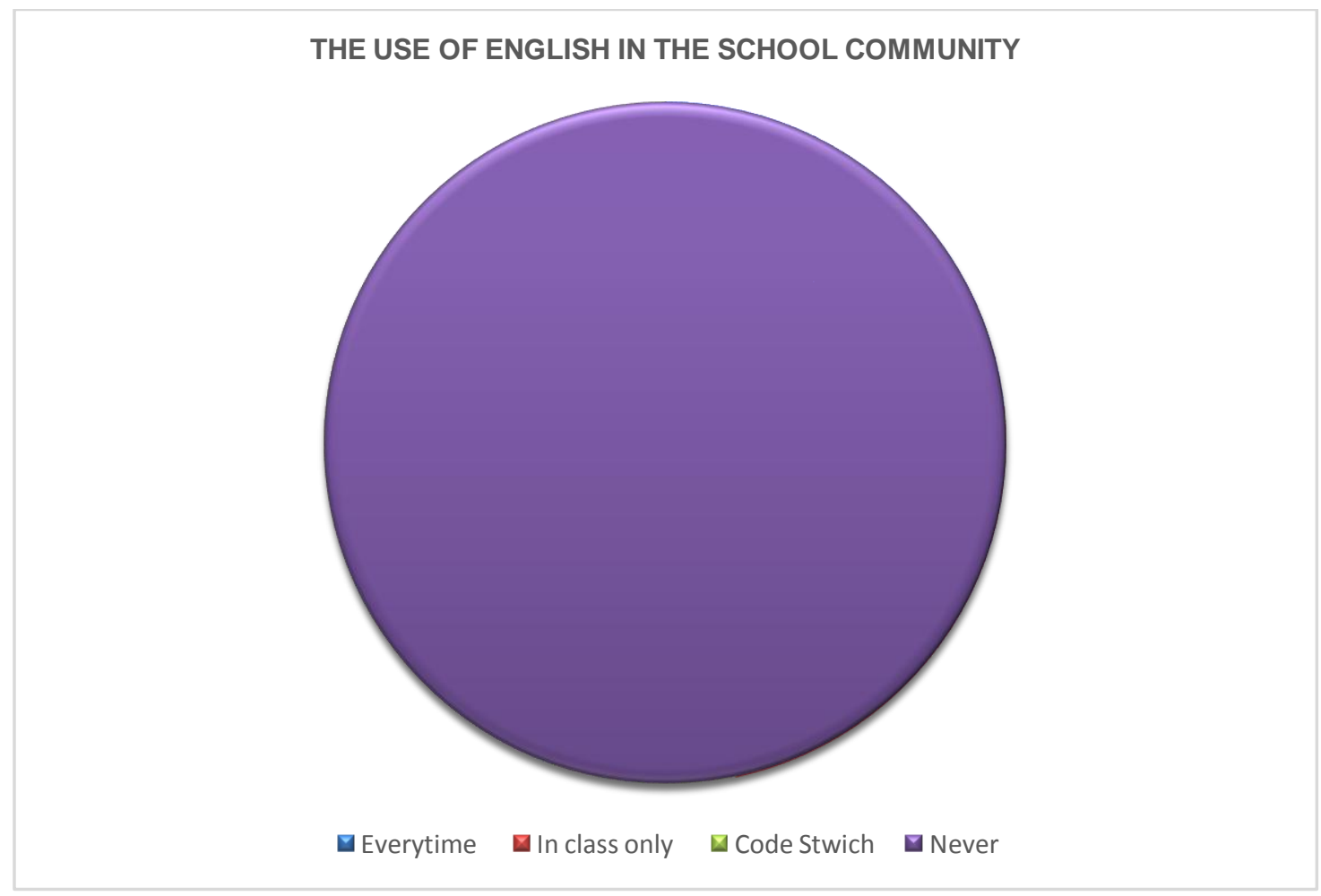

\section{Fig 1. The use of English in the school community}

The findings have revealed that the respondents like English because it is a language that facilitates broader communication with their friends, teachers and the community at large. Although not all learners are good English speakers, there is an indication that learners are intrinsically motivated to speak at all time since some of them are from different cultural and linguistic backgrounds and tribes or communities and most of the subjects are taught in English. The findings from observation also indicate that learners who seems to be active and loud in the class tend to participate well and have a good command of spoken English, thereby being good English readers comparing to the quiet and shy learners. The findings from both interviews and questionnaires indicates that learners especially the female leaners like to read novels and short stories for fun and to improve their speaking and reading skills, whereas the boys only preferred to read sport magazine and newspapers. This suggests that girls do more extensive reading than boys. The fact that girls read extensivelymore than boys, girls tend to be good English speakers and whichrelates to Chomsky's (1972) claim that, children who read a variety of rich and complex materials benefits from a range of linguistic inputs that is available to the non-literacy child. Although there is a library at school it is only stocked with a few English literatures and relatively limited literature in the home language. This discourages learners to use the library because they feel there is nothing to go there for.Other participating learners indicated that it is not easy to communicate in English when they are at the play field because they get excited and then start to code-switch from English to their home language. 6 learners who reside in town said that they are exposed to English on TV, radios and sometimes their neighbours speak in English with them. While the remaining 4 who resides in rural areas pointed out that when they go home they hardly speak English because people there speak in their own vernacular languages. 


\section{ii. School as a supporting English learning environment}

All learners seem to be confident of speaking and reading Englishlanguage but they feel that there is still more to learn.One of the respondents complained that sometimes the teacher speaks so fast, and this leads to learners failing to catch up with what is being said. Two others confessed that they do not really know how to pronounce some of the words when reading, that is why they do not really feel they are English speakers, "there is still so much to learn", said Ndapewa.

The language teachers revealed that the classroom environment does not allow them to have class libraries and book corners because the space is covered by learners who are overcrowded in the classrooms. In addition, there are no book shelves in the classroom or the school to enable them to set up reading corners classroom libraries. Teachershave introduced both intensive and extensive reading exercises in the class for learners to practice reading. They encourage learners to read in order to enhance their understanding and broaden their knowledge in all 4 skills (reading, speaking, writing and listening) of the language. They also motivate learners to use dictionary to improve their vocabulary and listen to the radio (English stations) to improve their pronunciation and listening skills. Teachers also introduces reading groups where learners lead in groups during classes. Besides that, there are factors that affects reading comprehension of learners such as: assessment activities but not teaching - whereby learners we just given reading tasks for assessment sake, but were not guided on acceptable reading conduct or proper pronunciations of words, vocabularies used in the reading comprehension tasks which is not guided, texts itself which is at time higher than the learners' level, learners motivation and interest on reading comprehension texts, availability of materials to use in reading comprehension and lack of test/questions for comprehension. Such as Dennis (2013) also narrated that text, interest and motivation, vocabularies are some of the factors affecting reading comprehension.

The research findings indicated that there are public libraries in the area i.e. the state library (regional library), the UNAM Northern Campus library and UNAM HP Campus library, but none of the teachers use the state library. The ones that use UNAM library are few that are doing part time study and they use it for their assignments. Most teachers do not read a lot except for daily newspapers and magazines.

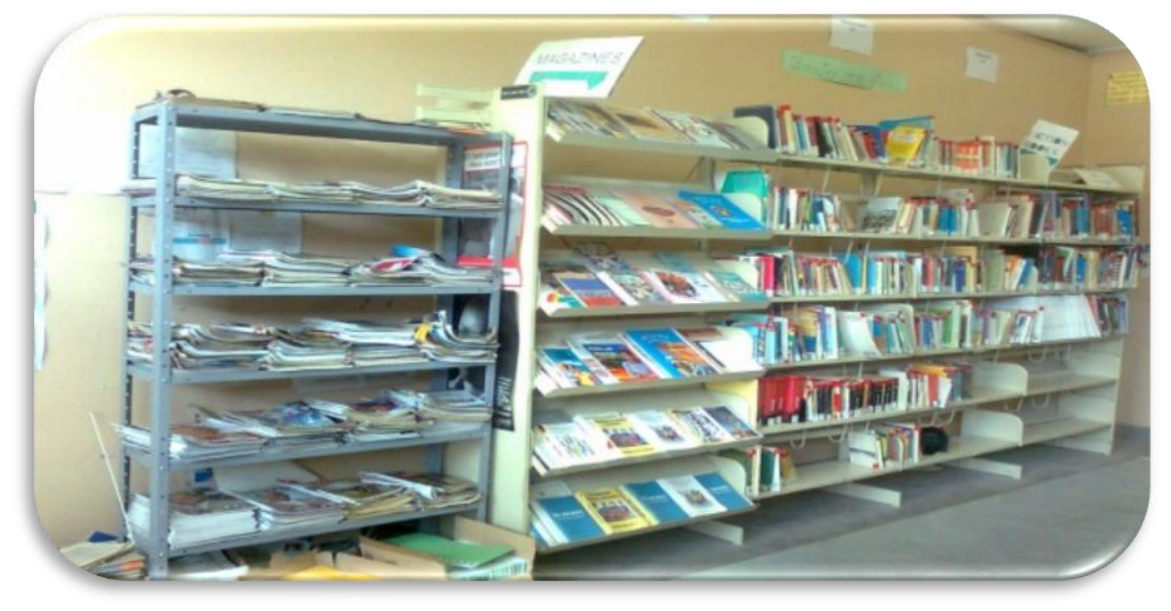

Fig 2: Language section of the school library (Newspapers, Magazines and Novels)

Teachers confirmed that learners at the school are good English speakers and they communicate well in the classroom. This enables them to explain matters better and the facilitation of learning has become easier due to learners' good command of English.

\section{iii. The influence of home language on second language acquisition}

Through the interview with seven teachers, it was noted that teachers especially those that teaches content subjects are sometimes forced to explain terms in the vernacular language example in natural science subjects, when teaching different types of weed, they explain them using their Oshiwambo names (indigenous names) for learners to understand them well. The Nigerian teachers said they only communicate in English since no one understands their native languages. The findingshave revealed that both languages (English and home language) are used at the school, because teachers and learners use to code switch between language when speaking to one another. This has brought up the language transfer whereby teacher transfer meanings (semantic transfer) to get the meaning of the targeted language i.e. teachers use the home language in the classroom to explain some of the items in English for learners to understand better. The fact that teachers like to code-switch when speaking, confirms the fact that as we talk to children, how we speak indicates how texts are constructed for particular purposes and situations, and thus learnerstask is to acquire an underlying structure from us teachers through imitation. This could be the reason as to why the learners under the observation often use mixed languagesat school.

\section{DISCUSSION}

There is a clear indication that English is the common language of teaching and communication at the school. There seem to be a big distinction between learners who are extroverts (they are free and confident) and introverts (shy and not comfortable) when speaking and reading. The teacher has shown favouritism to learners who are good speakers of 
English and although this is normal, it is not a good indication of learning to other learners who are trying to improve their language proficiency. Although there is no indication that learners learn in groups, there seem to be no indication that they are well guided on reading by their teachers. Literature indicates that when learners work cooperatively and collaboratively, they achieve higher levels of learning and this manifested itself. Learners tend to beactively involved in the language learning which results in good results. The classroom was found to be a good environment which is free from boasting and discriminations, although with a little favouritism and feel of superiority from extroverted learners. The findings revealed that, English teachers provide teaching methods that enable learners to read, write, speak and listen. These methods are taught in learner centred way, whereby learners participate and discuss with others in groups. In this way, language is brought to learners from learners themselves, learning from each other as they speak new words, and through reading and discussing ideas in English. Although the teacher sometimes intervene in learners reading and speaking for the purpose of correction, she does not really entice production from learners and there is a need for guided reading practice form the teacher's side which will encourage and motivate learners to produce. There is also an indication that the teacher wanted to produce Optimal Monitor ${ }^{3}$ users, who use their 'Monitor' when it is appropriate and not to be too much conscious about their grammar in normal conversations and thus they can do self-correction and self-learning. The teacher scaffoldslearning with well-structured activities (questions build from lower-order to higher-order questions) that allows comprehensible input that is at 'level i+1'to take place, especially for the lesson observed in Grade 6 . This is an indication that, well planned activities allow learners to build on what they know and go a little beyond where they are, then the learning context is good for additional language because we can expect learners to produce and that is what is happening in most cases at the school. The findings indicate that teachers use error based exercises which according to Falk (1979) are important in language acquisition as "only through errors can the learner test hypotheses, revise them, and continue to develop' (p.144). This is very important because through this monitor and modification process learners develops language awareness that enable them to consciously acquire the language, which helps in learning. The school environment is a good motivator when it comes to English second language because learners in most cases communicate in English with one another and when they don't, they are often seen switching codes. That then supports the statement made earlier that the grammar of both language contrast a lot, meaning that when learner use different code, they sometimes do it unconsciously and very well that in speaking that it does not interfere with their writing. The communication during the assembly is normally done in both languages, and this serves as a reflection that, although English is the official language in the school, other local languages are respected without taking up its (English) place in the school community. Beside the teachers' immediate correction of errors in the classroom and code switching when teaching and addressing learners, the school reading culture is found lacking. To start with, the findings have revealed that the school library has a shortage of English reading materials and learners hardly visit those sections because there interesting or/and new books and novels to read. This situation is not good for learners who are from communities where reading is not prioritised and modelled at home. These learners need to be in a good reading environment whereby they can see, walk and feel reading wherever they are. This enables them to be good readers and good English speakers in a long run. The classroom environment also does not support reading because there is a lack of equipment (cardboards) to set up books corners and classroom libraries and that the classrooms are overcrowded. Teachers also do not encourage learners to read by taking them to the school library and encourage book review every week. This situation is not encouraging learners to learn English on their own and does not give a good picture to the school. Krashen (1985) emphasises the importance of promoting acquisition by providing learners with appropriate comprehensive input. One alternative is for teachers to ensure that learners are provided with enough reading materials at school and that their learning is monitored throughscaffold activities that enable learners to learner complex terminologies, and analyse the syntax use sophisticatedly.

\section{CONCLUSION}

This study has offered tentative support of Krashen's Second Language Acquisition. Hislnput hypothesis, Affective filter hypothesis, and Monitor hypothesis, were observed and used to support ideas presented here and have proven that language can only be acquired and learned effectively when it is supplied with tools which allow learners to be themselves and to build on what they know without a lot of interventions and interferences from the second and third party. This study served as a reflection for English teachers teaching practices more specifically on reading if they are effective or not. The findings indicate that the provision of well-structured classroom activities containing comprehensible input structures a bit beyond the learners current level - and a low affective filter to allow them to acquire the second language easily. Moreover, error-based activities help learners to test hypothesis, revise and modify them and in the process develop good language awareness skills that help them to acquire and learn the language consciously. This paper suggests that a good supporting environment for reading, which is scaffold by enough assistance by the teachers and peers helps learners develop good language acquisition and learning skills.

\section{REFERENCES}

1. Cazden, C. B. (1992). Whole language plus: Essays on literacy in the United States and NewZealand. New York: Columbia University.

2. Chomsky, C. (1972). Stages in language development and reading exposure. In Minami, M. K. \& Kennedy, P. B. (1991). Language issues in literacy and Bilingual or multicultural education. Cambridge: Harvard Educational Review.

\footnotetext{
${ }^{3}$ The Monitor Hypothesis, Krashen's idea that the language that we have consciously learned acts as an editor in situations where learner has enough time to edit.
} 
3. Cohen, L. Manion, L. \& Morrison, K. (2000). Research Methods in Education (5 $5^{\text {th }}$ ed). London: Routledge.

4. Cunningham, A. \& Stanovich, K. (2003). Reading can make you smarter. Retrieved on January 23, 2006, from, 53 (4) http://www.naesp.org/ContentLoad.do?contentld=108=print

5. Donato, R. (1994). Collective scaffolding in second language learning. In J.P. Lantolf \& G. Appel (Eds.), Vygotskian approaches to second language research (pp. 33-56). Westport: Ablex Publishing.

6. Falk, J. S. (1979). Language acquisition and the teaching and learning of writing. College English 41. $436-447$.

7. Greenman, J. (1998) Caring space, learning places: Children's environment that works. Redmond: Exchange Press.

8. Johnston, R.B., \& Christensen, L. B. (2007) Educational research: Quantitative, qualitative and mixed approaches. ( $2^{\text {nd }}$ ed.). Boston: Pearson.

9. Krashen, S.D. \& Terrell, T. D. (1983). The Natural Approach: Language acquisition in the classroom. London: Prentice-Hall International Ltd.

10. Krashen, S.D. (1981). Principles and practice in Second Language Acquisition. London: Prentice-Hall International Ltd.

11. Krashen, S.D. (1981). Second Language Acquisition and Second Language Learning. Oxford: Pergamon.

12. Krashen, S.D. (1982). Principles and Practice in Second Language Practice in Second Language Acquisition. Oxford: Pergamon.

13. Krashen, S.D. (1985). The Input Hypothesis: Issues and Implications. New York: Longman.

14. Lightbown, P.M. \& Spada, N. (1999). How languages are learned (2 ${ }^{\text {nd }}$ ed.). Oxford: Oxford University Press.

15. Murray, S. (2006). Extract from an evaluation document. Grahamstown: Rhodes University.

16. Rhodes University. (2010). Core Text 1: Acquiring language and literacy. Grahamstown: Rhodes University.

17. Schultz, R. (2007). Stephen Krashen's Theory of Second Language Acquisition. Retrieved on April 27, 2010, from http://www.sk.com.br/sk-krash.html

18. Schumm, J.S. (Ed.). (2006). Reading assessment and instruction for all learners. New York: Guilford Press.

19. Vygotsky, L. S. (1981). The genesis of higher mental functions. In Wertsch, J.V. (Ed). The concept of activity in social psychology. 144-188. Amonk, NY: ME. Sharpe, Inc.

20. Vygotsky, L.S. (1978). Mind in society: The development of higher psychological processes. In Cole, M., JohnSteiner, V., Scribner, S. \& Souberman, E (Eds). Cambridge: Harvard University Press.

21. Wilson, R. (2000). A summary of Stephen Krashen's "Principles and Practice in Second Language Acquisition". Retrieved on April 27, 2010, from http://www.languageimpact.com/articles/rw/krashenbk.htm

Authors biographies:

1. Alleta Hautemo is lecturer at the University of Namibia's Education in Language, Humanities and commerce Department. She holds a Masters of Education in applied linguistics from Rhodes University. She is currently pursuing her PhD in Language Education with focus on Computational Linguistics with Stellenbosch University, South Africa..

2. Lukas Homateni Julius is a lecturer at the University of Namibia's Language Centre. He holds a masters of Education in English Language Teaching from Rhodes University, South Africa. Heis currently pursuing his PhD English Language Teaching with the University of the Western Cape, South Africa.

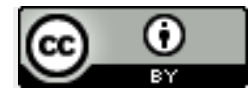

This work is licensed under a Creative Commons Attribution 4.0 International License.

$$
\text { DOI : 10.24297/jal.v7i2.4431 }
$$

